\section{Toxic effects of interferon administered intrathecally}

Multiple sclerosis is a neurological disease of unknown aetiology with signs of defective immunoregulation. Studies with immunologically active agents and immunosuppressive drugs have been carried out. Interferons, of which there are at least three types $(\alpha, \beta$, and $\gamma)$, are antiviral, cytostatic, and immunomodulatory proteins. The impaired production of interferon in patients with multiple sclerosis ${ }^{1}$ has prompted follow up trials of treatment with interferon in these patients. ${ }^{2}$ Since only $2-4 \%$ of interferon injected intramuscularly passes the blood-brain barrier, intrathecal administration has been used to obtain higher concentrations in the cerebrospinal fluid. Exogenous interferon- $\beta$ given intrathecally appears to be fairly nontoxic. ${ }^{3}$ We report our recent experience with intrathecal administration of interferon- $\alpha$.

\section{Patients, methods, and results}

We studied five severely disabled patients (two men, three women, mean age 34.8 years) with chronic progressive multiple sclerosis. The diagnosis was based on the criteria of Schumacher $e t$ al, and the neurological deficit of the patients was evaluated before each administration of interferon according to the scale of Fog and Raun. Lumbar puncture was done weekly and each patient received intrathecally increasing doses $(0 \cdot 1,0 \cdot 3,1 \cdot 0$, and $3.0 \times 10^{6} \mathrm{IU}$ ) of human leucocyte interferon- $\alpha^{4}$ diluted in $5 \mathrm{ml}$ physiological saline. The duration of follow up in each patient was three months.

Cerebrospinal fluid variables before each dose of interferon

\begin{tabular}{|c|c|c|c|c|}
\hline \multirow{2}{*}{$\begin{array}{l}\text { Case } \\
\text { No }\end{array}$} & \multicolumn{4}{|c|}{ Dose of interferon $\left(\times 10^{6} \mathrm{IU}\right)$} \\
\hline & $0 \cdot 1$ & $0 \cdot 3$ & $1 \cdot 0$ & $3 \cdot 0$ \\
\hline \multicolumn{5}{|c|}{ Leucocyte (and erythrocyte) count $\left(\times 10^{8} / \mathrm{l}\right)$} \\
\hline $\begin{array}{l}1 \\
2 \\
3 \\
4 \\
5\end{array}$ & $\begin{array}{l}15(0) \\
8(0) \\
8(2) \\
0(53) \\
1(3)\end{array}$ & $\begin{array}{l}22(0) \\
17(0) \\
21(1) \\
1(3) \\
44(133)\end{array}$ & $\begin{array}{c}44(5) \\
31(0) \\
43(4) \\
3(14) \\
23(6)\end{array}$ & $\begin{array}{c}2(34) \\
53(4)\end{array}$ \\
\hline \multicolumn{5}{|c|}{ Total $\operatorname{IgG}(m g / l)$} \\
\hline $\begin{array}{l}1 \\
2 \\
3 \\
4 \\
5\end{array}$ & $\begin{array}{r}96 \\
144 \\
160 \\
25 \\
174\end{array}$ & $\begin{array}{r}125 \\
78 \\
202 \\
33 \\
155\end{array}$ & $\begin{array}{r}131 \\
72 \\
165 \\
38 \\
149\end{array}$ & $\begin{array}{l}156 \\
190\end{array}$ \\
\hline \multicolumn{5}{|c|}{ Ratio of $\operatorname{IgG}$ to protein } \\
\hline $\begin{array}{l}1 \\
2 \\
3 \\
4 \\
5\end{array}$ & $\begin{array}{l}0 \cdot 16 \\
0 \cdot 26 \\
0 \cdot 16 \\
0 \cdot 06 \\
0 \cdot 27\end{array}$ & $\begin{array}{l}0.18 \\
0.14 \\
0.32 \\
0.07 \\
0.26\end{array}$ & $\begin{array}{l}0 \cdot 22 \\
0 \cdot 14 \\
0 \cdot 19 \\
0 \cdot 06 \\
0 \cdot 24\end{array}$ & $\begin{array}{l}0.22 \\
0.24\end{array}$ \\
\hline
\end{tabular}

Fever $\left(38-39^{\circ} \mathrm{C}\right)$ was seen in all patients. It began six to eight hours after the lumbar puncture and lasted for five to seven hours. Most patients experienced another, lower peak of fever $\left(37 \cdot 5-38 \cdot 5^{\circ} \mathrm{C}\right) 40-48$ hours after the injection. The fever was resistant to conventional antipyretics such as aspirin and indomethacin and was consistently associated with an obvious, transient deterioration in physical signs. Patients complained of extreme fatigue and increased need of help with the simplest activities of daily living. The adverse reaction was dose dependent and subjectively unbearable after doses that exceeded $0.3 \times 10^{6}$ IU. The symptoms disappeared in the 24 hours after the temperature fell to below $37 \cdot 0^{\circ} \mathrm{C}$ and no residual deficit was found on examination six days after the administration of the interferon. Threec patients dropped out before the fourth lumbar puncture, one because of acute worsening of the basic condition, one because of depressive mental symptoms, and the third because respiratory difficulties had occurred in the two patients who had received the final injection of $3 \times 10^{6} \mathrm{IU}$ interferon. $D$

The table shows the changes in the cerebrospinal fluid during thees treatment. Four patients developed lymphocytic pleocytosis; the fluctuation in total IgG and total protein concentrations was not significant.

\section{Comment}

The extreme sensitivity of patients with multiple sclerosis to moderate changes in body temperature is well known. The effect has $\widetilde{-}$ been proposed to be due to a neuroelectric block in marginally@ conducting demyelinated nerve fibres. Intramuscular injections of $3 \times 10^{6}$ IU interferon- $\alpha$ cause a rise in body temperature as well as unpleasant influenza-like symptoms. ${ }^{5}$ The febrile response after.

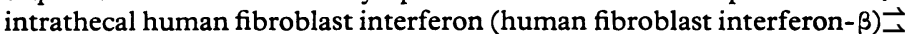
in patients with multiple sclerosis was not reported to be associated with severe adverse reactions. ${ }^{3}$ This difference, however, cannot be explained by differences in interferon preparations, since the fevers 3 after intramuscular human leucocyte interferon- $\alpha$ and humani fibroblast interferon- $\beta$ appear to be similar. A more likely explanation is that only severely disabled patients were selected for our trial.

We are unable to draw conclusions on the therapeutic value of intrathecally administered interferon owing to the selection and?

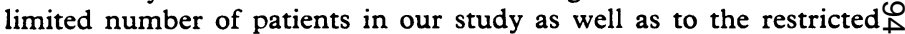
observation period. We suggest, however, that in further trials when human leucocyte interferon- $\alpha$ is used intrathecally any side effects $ᄋ$ should be carefully considered and a single dose should not exceed $\vec{\bullet}$ $0.3 \times 10^{6} \mathrm{IU}$.

I Salonen R, Ilonen J, Reunanen M, Nikoskelainen J, Salmi A. PPD-, PWM-, and PHA-induced interferon in stable multiple sclerosis:association with HLA-Dw 2 antigen and clinical variables. Ann Neurol $\overrightarrow{0}$ $1981 ; 11: 279-84$

${ }^{2}$ Abb J, Deinhardt F, Zander H, et al. Trials of interferon therapy for multiple sclerosis. F Infect Dis 1982;146:109-15.

${ }^{3}$ Jacobs L, O'Malley J, Freeman A, Murawski J, Ekes R. Intrathecal interferon in multiple sclerosis. Arch Neurol 1982;39:609-15.

${ }^{4}$ Cantell K, Hirvonen S, Koistinen V. Partial purification of humano leukocyte interferon on a large scale. Methods Enzymol $1981 ; 78: 499-505$.응

5 Scott GM, Secher DS, Flowers D, Bate J, Cantell K, Tyrrell DAJ. Toxicity of interferon. Br Med $\mathcal{f} 1981$;282:1345-8.

(Accepted 5 fanuary 1983)

Department of Neurology, University of Turku, Turku, Finland

J RUUTIAINEN, MD, assistant physician

$M$ PANELIUS, $M D$, associate professor

National Public Health Institute, Helsinki, Finland

K CANTELL, MD, professor of virology

Correspondence to: Dr J Ruutiainen.
EMPLASTERS-By Emplasters, here, I do mean things glutinative, and they are quite contrary to things cleansing. They are of a far more glutinous and tenacious substance. They differ from things stopping because they do not stop the pores so much, as stick to them like Birdlime. They have a certain glutinous heat, tempered both with coldness and moisture. From these plasters take their names. Their taste is either none at all, or not discernible whether hot or cold, but fat, insipid, or without taste, or sweet, and viscous in feeling. Their use is to stop flowing of blood, and other fluxes, to cause suppuration, to continue the heat, that so tumours may be ripened. Also they are mixed with other medicines, that they may the better be brought into the form of an emplaster, and may stick the better to the members. (Nicholas Culpeper (1616-54) The Complete Herbal, 1850.)

sow THISTLE grows in gardens and manured grounds, sometimes by old walls, pathsides of fields, and high ways.

This is under the influence of Venus. Sow Thistles are cooling, and somewhat binding, and are very fit to cool a hot stomach, and ease the pains thereof. The herb boiled in wine, is very helpful to stay the N dissolution of the stomach, and the milk that is taken from the stalksN when they are broken, given in drink, is beneficial to those that are short winded, and have a wheezing. Pliny saith, That it hath caused the gravel and stone to be voided by urine, and that the eating thereof helps a stinking breath. The decoction of the leaves and stalks causes abundance of milk in nurses, and their children to be well coloured.? The juice or distilled water is good for all hot inflammations, wheals, 꾸 and eruptions or heat in the skin, itching of the haemorrhoids. The juice boiled or thoroughly heated in a little oil of bitter almonds in the peel of a pomegranate, and dropped into the ears, is a sure remedy for deafness, singings, \&c. Three spoonfuls of the juice taken, warmed $\stackrel{\varrho}{\circ}$ in white wine, and some wine put thereto, causes women in travail to have so easy and speedy a delivery, that they may be able to walk presently after. It is wonderful good for women to wash their faces with, to clear the skin, and give it a lustre. (Nicholas Culpeper (161654) The Complete Herbal, 1850.) 